\title{
Constraints to applying systems thinking concepts in health systems: A regional perspective from surveying stakeholders in Eastern Mediterranean countries
}

\author{
Fadi El-Jardali ${ }^{1,2,3,4,5^{*}}$, Taghreed Adam ${ }^{6}$, Nour Ataya ${ }^{1}$, Diana Jamal $^{1,2}$, Maha Jaafar $^{1}$
}

\begin{abstract}
Background: Systems Thinking (ST) has recently been promoted as an important approach to health systems strengthening. However, ST is not common practice, particularly in Low- and Middle-Income Countries (LMICs). This paper seeks to explore the barriers that may hinder its application in the Eastern Mediterranean Region (EMR) and possible strategies to mitigate them.

Methods: A survey consisting of open-ended questions was conducted with a purposive sample of health policymakers such as senior officials from the Ministry of Health $(\mathrm{MoH})$, researchers, and other stakeholders such as civil society groups and professional associations from ten countries in the region. A total of 62 respondents participated in the study. Thematic analysis was conducted.

Results: There was strong recognition of the relevance and usefulness of ST to health systems policy-making and research, although misconceptions about what ST means were also identified. Experience with applying ST was very limited. Approaches to designing health policies in the EMR were perceived as reactive and fragmented (66\%). Commonly perceived constraints to application of ST were: a perceived notion of its costliness combined with lack of the necessary funding to operationalize it (53\%), competing political interests and lack of government accountability (50\%), lack of awareness about relevance and value (47\%), limited capacity to apply it (45\%), and difficulty in coordinating and managing stakeholders (39\%).

Conclusion: While several strategies have been proposed to mitigate most of these constraints, they emphasized the importance of political endorsement and adoption of ST at the leadership level, together with building the necessary capacity to apply it and apply the learning in research and practice.

Keywords: Systems Thinking (ST), Health Systems, Eastern Mediterranean Region

Copyright: $\odot 2014$ by Kerman University of Medical Sciences

Citation: El-Jardali F, Adam T, Ataya N, Jamal D, Jaafar M. Constraints to applying systems thinking concepts in health systems: A regional perspective from surveying stakeholders in Eastern Mediterranean countries. Int J Health Policy Manag 2014; 3: 399-407. doi: 10.15171/ijhpm.2014.124
\end{abstract}

Article History:

Received: 18 July 2014

Accepted: 13 November 2014

ePublished: 18 November 2014

*Correspondence to:

Fadi El-Jardali

Email: fe08@aub.edu.lb

\section{Key Messages}

Implications for policy makers

- Political endorsement and adoption of Systems Thinking (ST) at the policy-making level is needed to improve the way health systems are functioning.

- ST has the potential to guard against the usual "quick fix" mentality that often dominates policy-making processes particularly in Low- and Middle-Income Countries (LMICs).

- The application of ST concepts entails building the capacity within policy-making institutions in using the relevant ST concepts and tools.

Implications for public

Systems Thinking (ST) is an approach to understanding how health systems components, contexts and actors interact and then applying this understanding to design interventions for improving health. Despite increased recognition of its potential to improve health, ST is not common practice in the Eastern Mediterranean Region (EMR). Political endorsement and adoption of ST at the leadership level, together with building the capacity to apply ST in research and practice are needed for advancing ST in Low- and Middle-Income Countries (LMICs).

\section{Introduction}

Recent years have seen growing interest in applying Systems Thinking (ST) principles to improve public health (1-3). Public health is the process of mobilizing and engaging local, regional, national and international resources to assure the conditions in which people live can be healthy. It includes three major fields: i) policy, as it is inherently a political enterprise that supplies services and allocates resources; ii) practice, as policies need to be implemented to create social action and organize service delivery; and iii) research, 
as interventions need to be developed and assessed on effectiveness and cost-benefit ratios (4). The World Health Organization's (WHO) Alliance for Health Policy and Systems Research has promoted ST as a strategic approach for health systems strengthening with a view to accelerating progress to achieve global and national health goals (5). However, health systems strengthening is complex, partly because there is no common understanding of what it means, what it involves, and what the most suitable approaches to strengthen health systems are, especially in Low- and Middle-Income Countries (LMICs) (6,7). Moreover, despite increasing examples of why health policies have failed to achieve their targets due to the way policies were designed or implemented (8-10), actions to address these recurring phenomena and learning from the past are very slow, particularly in LMICs $(1,11,12)$.

Following the World Health Report (2000), health systems are defined as the people, institutions and resources, arranged together in accordance with established policies, to improve the health of the population they serve, while responding to people's legitimate expectations and protecting them against the cost of ill-health through a variety of activities whose primary intent is to improve health (13). Health systems share the characteristics of complex adaptive systems $(1,5,11,14)$. "Complexity" arises from health systems' interconnected parts and "adaptivity" from their ability to adjust and change in ways that are unpredictable and uncontrollable (15). They are constantly changing, sensitive to pre-existing conditions, self-organizing, and governed by feedback and the actions and reactions of health systems actors. Due to all of these characteristics, it is often difficult to develop apriori an effective policy without understanding health systems, making systems "policy resistant", especially when actors within systems have competing goals (5). As such, taking into account the interconnectedness and relationships between the different components and stakeholders of health systems is important to achieve the desired changes and goals $(10,11,16)$. ST has been long used in other disciplines such as in business, engineering, and physics to offer conceptual and methodological approaches to think through and understand how complex systems respond to the introduction of new policies or events (2). It provides an approach to problem solving that views problems as part of a wider dynamic system (5). It therefore requires a deeper understanding of the behaviour of complex adaptive systems in designing, evaluating and implementing health policies to maximize health and health equity (16).

Several suggestions have been made for making ST concepts a common practice in the health field, though mainly derived from high-income countries (1). They included revisiting traditional funding categories to explicitly encourage a more integrative, systems-based view of financing; supporting diverse networks by encouraging collaborations and partnerships that span traditional disciplines and perspectives; and addressing political and social factors that influence the use of ST such as bureaucracy, people's fears (e.g. apprehensions about job loss), conflicts in mandates and governing rules among organizations, and factors in academic environments that may limit adoption of systems approaches (1).

Given the increased recognition of the importance and relevance of ST for strengthening health systems in LMICs in recent years, expressed by the 2009 WHO publication (5) and other recent publications on the topic $(3,9,17,18)$, and using the EMR as a case study, this paper seeks to gain a better understanding of: 1) how ST concepts have been received and used by health systems stakeholders including policy-makers such as senior officials in the Ministry of Health $(\mathrm{MoH})$, researchers and other stakeholders such as civil society groups and professional associations, particularly in LMICs in recent years; 2) what in their view are the key enablers and barriers that may support or hinder its wider adoption in health systems research and practice; and 3) what are the possible strategies to address the perceived constraints. Despite the diversity in countries of the region with regard to income, development, health and environmental conditions, most countries from the EMR are classified as LMICs. Health systems of most countries in the region share the basic characteristics of LMICs, including substantial healthcare burden, limited financial resources, weak government institutions, reliance on external sources of funding (e.g. donations), shortages in the health workforce and weak human resources management systems. Additionally, several countries from the region face political upheaval and social unrest and the health sector in these countries is dominated by emergency-oriented activities (19). As such, studies from the region would help provide important insights to inform research and practice on ST approaches in other LMIC settings.

\section{Methods}

A survey consisting of open-ended questions was conducted with health systems stakeholders including policy-makers, researchers and other stakeholders from ten countries from the EMR: Algeria, Bahrain, Egypt, Iraq, Jordan, Lebanon, Oman, Palestine, Sudan, and Yemen. The questions were guided by the principles laid out in the 2009 WHO's Alliance for Health Policy and Systems Research report on "Systems thinking for health systems strengthening" (5).

The survey questions covered the following issues: what policy-makers, researchers, and other stakeholders perceive the meaning of ST to be and its applicability in addressing health systems issues in their country; how ST principles differ, if any, from their usual practice in designing and evaluating interventions; in their view, what the main challenges and enablers to using ST in health systems research and everyday policy-making are; what strategies can be used to enhance its use in the context of their country's political, social and economic environment; and whether there are needs for specific tools to enhance its use in the region. In addition, respondents were asked to provide an example where ST was used for addressing health priorities in their country, and another example where ST was not used but was needed, see Appendix 1 for the questionnaire.

The survey was originally developed in English and translated to Arabic by a professional translator. Questions were backtranslated to English, minimal differences were detected. The questions were then pilot-tested with a health systems and policy researcher from the region who provided input on survey questions and helped to ensure face validity of the survey. Following the pilot, probing examples were added to questions and changes were made to the English and Arabic wording of questions to further clarify the meaning to policymakers, researchers and other stakeholders from the region. 
Participants were selected using purposive sampling. The target sample size ranged from eight to 15 participants from each country. A sampling frame was established to determine the selection criteria for respondents. It was adapted from a similar tool (20) that was used in previous studies in the $\operatorname{EMR}(21,22)$. The sampling frame covered persons occupying positions corresponding to the six building blocks of the health system, as defined by WHO: service delivery, health workforce, health information, medical technologies, health financing, and leadership and governance (23). It included the following categories: 1) policy-makers from different settings at the national level, such as senior officials (i.e. elected officials, political staff, or civil servants) in the $\mathrm{MoH}$ and other healthrelated ministries; 2) other stakeholders including managers in civil society groups; Non-Governmental Organizations (NGOs); professional associations; donor agencies; and 3) researchers from the $\mathrm{MoH}$, national research institutions, and universities.

Policy-makers' and other stakeholders' names and corresponding emails were identified by performing a thorough internet search of the websites of $\mathrm{MoH}$, NGOs, and professional associations. The compiled lists were validated by members of the Evidence Informed Policy Network EMR (EVIPNet EMR) - an established social network that encourages the use of evidence in the policy-making process in each of the study countries. This approach was successfully used to identify policy-makers and other stakeholders in previous studies from the region (21).

Researchers were identified from a database for health systems and policy researchers from the EMR (22). The database was compiled through a search of corresponding authors who had published health systems and policy research articles in the EMR between the years 2000 and 2008, in local or international journals. The search strategy was conducted on Medline and Embase and was developed to optimize sensitivity and specificity (24).

Respondents were targeted by email to request their participation. If they agreed to participate, they were sent another email with a brief overview of ST, its main concepts and relevance for health systems, in both Arabic and English, as an excerpt from the report in addition to the questions to sensitize respondents on the topic, see Appendix 1 for the questionnaire. The survey was administered in one of two forms, as an interview by phone or face-to-face or as a selfadministered questionnaire, when neither phone nor faceto-face interview was feasible or when it was the preferred option by the respondents. The questionnaire was identical, with clear instructions included in the written form. In the case of no response to the invitation email, a single reminder was sent two weeks after the initial invitation. Given the well-documented advantages of using phone interviews in qualitative research, including cost-effectiveness in terms of time and money, minimum disruption to respondents, flexibility, as well as comparability with face-to-face interviews $(25,26)$, this was the most prevalent approach for data collection (58\%), followed by self-administered questionnaires (24\%) and face-to-face interviews (18\%). Previous studies demonstrated the comparability of interviews with written surveys $(27,28)$. Additionally, we did not notice differences between the responses provided by these groups. Furthermore, respondents in written surveys included examples, explanations and justifications to support their answers, as did respondents in face-to-face or phone interviews.

During the interviews, responses were recorded by extensive note-taking. Responses were then entered by the interviewer the same or next day in order to ensure accuracy of transcribing data as delay in transcription can affect the quality of the data, for example by misreading handwritten notes $(25,29)$. Upon their request, interviewees were provided with a transcript of their responses for verification; minor corrections were made to the transcripts. Responses collected through self-administered questionnaires were directly appended to the same dataset. Microsoft Excel was used for data entry and analysis. Thematic analysis was conducted. Themes were identified based on the study objectives and survey questions. The findings were brought together in a spreadsheet to better manage the data. First, open coding was conducted, whereby findings were broken into chunks that relate to different concepts or ideas. In this stage, the concepts or ideas were applied to the data by annotating the transcripts with colour codes to distinguish the different concepts embedded in the data. Axial coding was then conducted, which involves organizing the emerging concepts into the appropriate themes (30). Recurring concepts and emerging patterns across respondents were then analysed. The frequency (percentage) of respondents mentioning the concept was reported. Illustrative quotations were identified to support the narrative description of the themes. Coding was conducted by one research team member. The analysis process was iterative; preliminary findings were discussed among research team members and further refinement of the analysis was conducted thereafter.

\section{Results}

A total of 62 respondents participated in the study out of 153 invited to participate with a response rate of $41 \%$ and ranging from $17 \%$ to $100 \%$ per country. Of the total, $23 \%$ were from Lebanon, $16 \%$ from Jordan, $13 \%$ from Iraq, and $11 \%$ from Egypt, see Table 1. Policy-makers represented $60 \%$ of the respondents, followed by researchers (27\%), other stakeholders (7\%) and four respondents with mixed affiliations (7\%): two policy-makers who also work as researchers and two policy-makers who at the same time hold positions at a donor or international organization. Fifty percent of the respondents were females and 50\% were males. The average years of experience for participants in their domains was $16.7 \pm 9.8$ years.

\section{How Systems Thinking (ST) concepts were perceived and use?}

Overall, respondents had a good general understanding of what ST means, although two (3\%) were first introduced to the term through our study. Box 1 illustrates how ST concepts were commonly described by respondents. Respondents acknowledged the advantages of using ST concepts in their respective domains. Particularly, they pointed out its potential for strengthening health systems through identifying and understanding health systems challenges from a systems perspective, taking into account the components of health systems and the relationships and interactions between them. Respondents also stated that ST could help health 


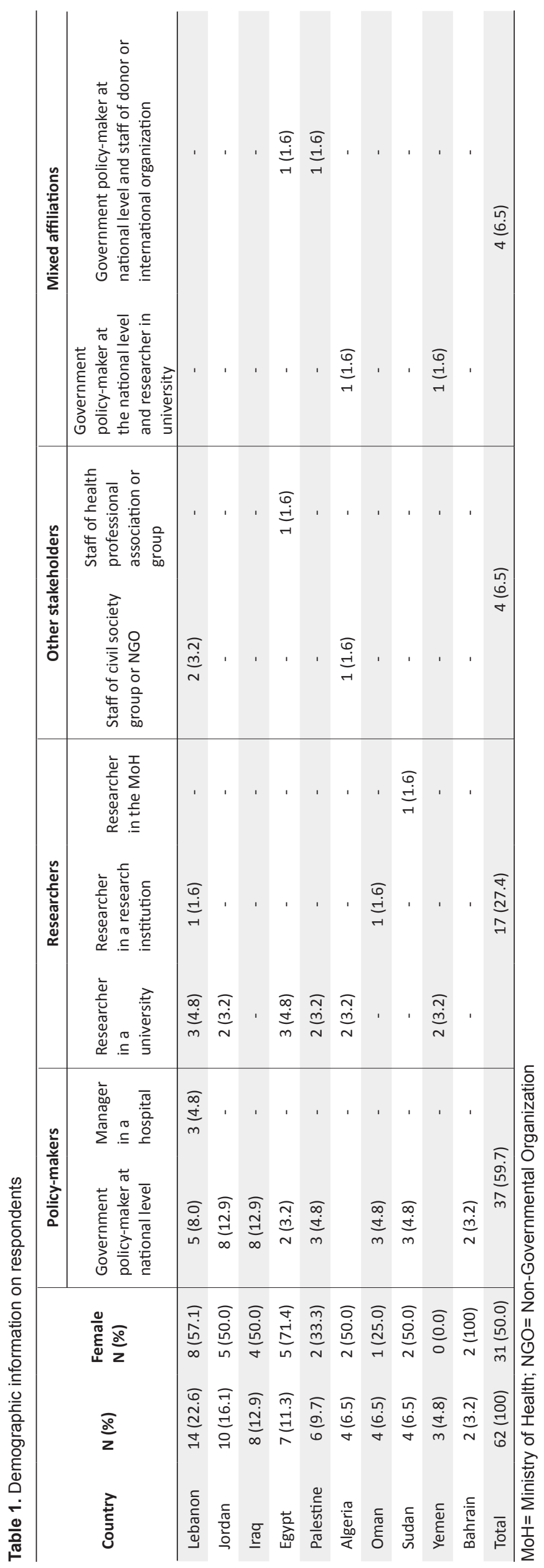

systems planners and implementers to anticipate how health systems may be influenced and how they may react to interventions. They pointed out that ST could also strengthen communication across different health systems stakeholders, which would minimize resistance and enhance ownership of interventions.

At the same time, policy-makers, researchers and other stakeholders alike had misconceptions and conflations between applying ST concepts and tools and general good management practices. For example, several respondents (17, $27 \%$ ) inferred that the "10 steps to applying ST" proposed in the WHO ST report (see Box 2) were synonymous to adopting and applying ST approaches and tools, while they are simply guiding steps for a comprehensive, systematic and iterative process for incorporating and applying ST concepts in research and policy-making. Box 3 illustrates some of these misconceptions.

Only three respondents (5\%), including a policy-maker, a researcher, and policy-maker with a position at a donor agency, identified applications of ST in designing or implementing health policies in their country (see Box 4 for examples), whereas most $(41,66 \%)$ reported that the current approach for designing and implementing policies looked at the health system through its individual components but did not look at the relationships and interactions amongst these components. Furthermore, nine policy-makers (15\%) described the current approach to designing and evaluating interventions to be reactive rather than proactive, as demonstrated by a policy-maker from Iraq:

"The current thinking depends on reactively finding solutions to health systems problems and usually the mechanisms set are unclear and imprecise".

When asked about the extent to which the "10 steps to ST" that were proposed in the WHO report were reflected in current practice the answer was mixed, most respondents (30,48\%), policy-makers, researchers and other stakeholders alike, suggested that the steps related to the design of interventions were more commonly used than those related to their

Box 1. Illustrations of how ST was described by researchers and policy-makers from the EMR:

- "Systems thinking is an approach to problem-solving through a comprehensive perspective to explore relationships within the health system" (Researcher from Yemen).

- "Systems thinking is a process by which all the elements of the health system are linked together to understand how each element affects the other" (Policy-maker from Jordan).

- "Systems thinking is a structured approach to map and forecast the size, type, weight, and direction of changes that are very likely to occur in known components of the health system as a direct result of interventions in that system" (Policy-maker from Lebanon).

- "The most important aspect of ST is including [health systems] stakeholders in dialogue and in designing and evaluating interventions" (Policy-maker and staff member at an international organization from Egypt). 
Box 2. "Ten Steps to Systems Thinking" proposed in de Savigny and Adam 2009:

\section{Intervention design}

1. Convene stakeholders representing each building block, plus selected intervention designers and implementers, users of the health system, and representatives of the research community

2. Collectively brainstorm possible system-wide effects of the proposed intervention taking into account feedback mechanisms, time delays, policy resistance, etc.

3. Conceptualize effects by mapping how the intervention will affect health and the health system through its subsystems

4. Adapt and redesign the proposed intervention to optimize synergies and other positive effects while avoiding or minimizing any potentially major negative effects

\section{Evaluation design}

5. Determine indicators that are important to track in the re-designed intervention (from process to issues to context) across the affected sub-systems

6. Choose methods to best track the indicators

7. Select designs that best manage the methods and fit the nature of the intervention

8. Develop plan and timeline by engaging the necessary disciplines and stakeholders

9. Set a budget for both intervention design and evaluation 10. Source funding to support the evaluation before the intervention begins

Source: de Savigny and Adam 2009 (3)

Box 3. Examples of some misconceptions around what ST means in practice among respondents:

- "ST means that [thinking about] every problem should be preceded by analysis of Strengths, Weaknesses, Opportunities, and Threats (SWOT) and by setting solutions through measurable and specific indicators" (Policy-maker from Iraq).

- "ST is to implement strategies and actions based on consensus in addition to monitoring and evaluation. It is [more] applicable in a pro-active [rather than a reactive] manner. It is not very suitable for urgent health events" (Policy-maker from Lebanon).

- "The six building blocks of the health system were taken into consideration in Sudan's health plan for the years 2012-7. Stakeholders were convened and they brainstormed to make sure that all those affected, including donors, are involved, which resulted in (...) providing technical and financial support" (Policy-maker from Sudan).

evaluation, although some policy-makers and researchers (7, $11 \%$ ) implied that these steps were conducted in a superficial way as reflected in the following quotes:

"Although steps [related to] evaluation are undertaken, they are mostly superficial and non-scientific" (Policy-maker from Jordan).
"At the national level, the health plan utilized steps 1 to 4 [on the design of interventions] but not in a systematic way. Stakeholders were convened and they brainstormed; however, they did not map and conceptualize effects of the intervention in the health system [in Palestine]. They also did not apply the ST approach systematically to examine relationships across components of the health system" (Researcher from Palestine).

While most respondents $(38,61 \%)$ perceived the "10 steps" to be a practical way to institutionalize ST concepts in research and practice, they emphasized the need for more accessible and practical guidance, including information about the available ST tools and approaches that can be used for the different steps, which would highly encourage their use. This was a common perception among more than half of the respondents from each domain.

Key barriers and enablers for applying System Thinking (ST) in research and practice and possible strategies to overcome barriers

Building capacity and awareness

Around half of the policy-makers and half of the researchers mentioned the lack of policy-makers' awareness and understanding of ST's main principles, tools, and added value $(29,47 \%)$ and the limited capacity to apply its principles and tools $(28,45 \%)$ as important challenges to wider applications of ST concepts, see Table 2. Specific examples of capacity gaps included the lack of skilled human resources in designing new interventions, understanding the complexity of health systems and how to think about and take into account the relationships and interactions across different components of health systems. However, it was perceived that both policymakers and researchers would be interested to learn about ST and how to apply its concepts and approaches in their country, if the opportunity arises.

Another related challenge is the lack of well-functioning health information systems and good quality data that can be used in designing and evaluating interventions (10, 16\%). Respondents $(20,32 \%)$ also felt that strengthening the existing health information system and health systems research is feasible, if dedicated efforts are directed to do so. This was mentioned by around one third of the policy-makers and one third of the researchers.

Political context was also seen as an important factor by respondents from all domains alike, where efforts to build capacity and awareness among policy-makers may be hindered by competing political interests, lack of accountability at the government level, lack of political stability in the region, and the high turnover at the government level, see Table 2.

Among the most commonly suggested strategies to overcome these barriers were: building capacity in using the relevant concepts and tools $(47,76 \%)$ and creating opportunities to sensitize and build awareness among various health systems stakeholders about the relevance and usefulness of ST in solving health systems problems $(32,52 \%)$. These strategies were mentioned by the majority of the policy-makers and the majority of researchers. Other suggestions included incorporating ST in graduate public health and health policy programs and creating opportunities for exchanging 
Box 4. Examples of how ST was applied in Lebanon

The following two quotes illustrate how a ST approach was used in implementing policies for generic drugs and tobacco control in Lebanon:

- "The program for generic drugs can be considered a success story for implementing interventions in Lebanon using a ST approach, in the sense that wider and different issues in the system were viewed and tackled when designing these interventions" (Policy-maker from Lebanon).

- "The policy on tobacco control looked at all aspects of the problem whether health, economic, social, etc... to derive a solution. We [researchers] also worked on networking with the media and developed good relationships with them. They advised us on which events to cover and who to talk to, they also advised on who would have a positive or negative view about the issue and the reasons behind their views. We also worked with civil society and politicians. The latter now contact us regarding other issues they face. If a ST approach had not been used, the tobacco control policy would probably not have worked" (Researcher from Lebanon).

experiences and learning from other countries where it is applied. For example, a policy-maker and a researcher suggested shadowing experienced professionals in order to build their capacity in applying ST concepts and tools in designing and evaluating interventions. Additionally, presenting policy-makers with examples where ST was used and made a positive difference was also mentioned as a potentially powerful approach to convince policy-makers and other stakeholders of the value of ST $(8,13 \%)$.

\section{Funding and sustainability}

A common perception among respondents was that the adoption of a ST approach was costly. Half of the respondents identified the lack of financial resources and reliance on earmarked external resources as a major barrier to adopting a ST approach and building the capacity to apply it, especially for evaluating the impact of new policies and programmes (33, 53\%), see Table 2. As a policy-maker from Palestine explained:

"Funding agencies require capacity-building and evaluation as part of funding criteria for projects, but they do not usually provide funding for these components. [Funding] is only provided for designing and implementing the intervention".

As an alternative to overcome this challenge, some respondents $(36,58 \%)$ suggested leveraging funding from local sources, including country offices of international organizations that may be willing to invest in providing technical and financial support to wider application of ST principles and approaches. This strategy was suggested by more than half of the respondents from each domain.

\section{Coordinating and managing partnerships}

Coordinating and managing conflicts in mandates, opinions and interests of various stakeholders $(24,39 \%)$ and ensuring their active involvement and support $(9,15 \%)$ were some of the main practical challenges to applying ST. Respondents also highlighted the value of acquiring new skills such as effective ways of convening health systems stakeholders to brainstorm, conceptualize and redesign interventions to maximize synergies. To overcome these challenges, they suggested that involving health systems stakeholders early on in the intervention's design phase and throughout the implementation process, agreeing on common goals, creating incentives, and establishing channels of communication, networking, and sharing of information may all contribute to better interaction and increased mutual benefits and interest.

\section{Discussion}

To our knowledge, this is the first study to elicit the views of various types of health systems stakeholders in LMICs on the use and relevance of ST for health systems in their settings. Although limited to the EMR, the inclusion of a diverse range of respondents from ten countries in the region can offer valuable insights for other countries with similar characteristics and context.

Our study showed that while there is general interest and acknowledgement of the relevance and value of ST for health systems research and policy-making, experience in applying it has been limited in the EMR. This finding is confirmed by recent studies that found very few practical experiences from LMICs $(3,11,12)$. The Alliance for Health Policy and Systems Research has been supporting various activities to build capacity to apply ST concepts and tools, with the objective of promoting wider use of the available methods that are applicable in LMICs $(3,31)$.

Furthermore, few respondents seemed to have a good grasp of what ST means and what the related concepts and tools are. However, despite sharing the overview on ST with respondents prior to the survey, misconceptions were noted where many respondents seemed to conflate applying ST tools and approaches (e.g. system dynamics modelling, social network analyses, concept mapping) with adopting good strategic management approaches or with undertaking the "10 steps to applying ST" proposed in the WHO 2009 report (5). Perhaps a factor that should not be underestimated is the language barrier, where the relevant literature and media for exchanging information are mostly available in English. Creating opportunities to sensitize health systems stakeholders about what ST is and how it can contribute to strengthening health systems, in appropriate language and format is, therefore, an essential step towards its wider adoption and use, as suggested in this study and as highlighted on several occasions $(1,5,12,31-33)$.

At the same time, findings showed that there exists willingness among policy-makers, researchers, and other stakeholders to support novel approaches to strengthening health systems, including the application of ST principles and approaches. The recent changes that are unfolding in some countries of the region, such as the Arab uprisings, may have presented a socio-political enabler for the progression towards health systems reforms (34). However, in order to build on this momentum, this study emphasized that additional efforts by governments, national and international funders, academic institutions and civil society are needed to contribute to the current momentum towards using stronger and more suitable methods and approaches to address health systems issues.

Findings emphasized the need for building capacity in using ST tools and approaches. While evidence on what works for 
Table 2. Barriers, enablers and strategies for applying ST concepts and tools (N, \%)*

\begin{tabular}{|c|c|c|}
\hline Barriers & Enablers & Strategies to promote use of ST concepts and tools \\
\hline $\begin{array}{l}\text { Contextual } \\
\text { Perceived costliness of applying ST concepts and } \\
\text { lack of funding to operationalize it (33,53\%) } \\
\text { Competing political interests and lack of } \\
\text { accountability at the government level (31,50\%) } \\
\text { Lack of policy-makers' awareness and } \\
\text { understanding of its principles and tools (29, } \\
47 \% \text { ) } \\
\text { Limited capacity to apply ST concepts and tools } \\
\text { ( } 28,45 \%) \\
\text { Lack of political stability in the region and high } \\
\text { turnover at the government level (20,32\%) } \\
\text { Practical } \\
\text { Difficulty in coordinating and managing conflicts } \\
\text { among health systems stakeholders (24, 39\%) } \\
\text { Lack of well-functioning information systems and } \\
\text { good quality data (10, } 16 \%) \\
\text { Difficulty in ensuring the active involvement and } \\
\text { support of health systems stakeholders (9, 15\%) }\end{array}$ & $\begin{array}{l}\text { Willingness and interest to learn } \\
\text { about ST among both researchers } \\
\text { and policy-makers ( } 24,39 \%) \\
\text { Readiness to innovate and } \\
\text { accept novel approaches for } \\
\text { strengthening health systems } \\
(15,24 \%) \\
\text { - } \quad \text { Local and international } \\
\text { organizations may be willing to } \\
\text { invest in technical and financial } \\
\text { support to wider application of } \\
\text { ST principles and approaches } \\
\text { (14, 23\%) } \\
\text { Possibility to strengthen data } \\
\text { sources and health information } \\
\text { systems (11, } 18 \%)\end{array}$ & $\begin{array}{l}\text { - } \quad \text { Create opportunities to build capacity in using } \\
\text { ST tools and approaches (47, 76\%) } \\
\text { - Seek additional funding to operationalize it in } \\
\text { research and policy-making (36,58\%) } \\
\text { Sensitize and build awareness among policy- } \\
\text { makers on its applicability and added value to } \\
\text { create a demand for its use (32,52\%) } \\
\text { Improve the availability and quality of health } \\
\text { systems data (20,32\%) } \\
\text { Establish a central entity at government level } \\
\text { to promote its use ( } 15,24 \%) \\
\text { Establish mechanisms for monitoring and } \\
\text { evaluation, with ST in mind (13, 21\%) } \\
\text { Consider governmental reforms, including } \\
\text { organizational restructuring (13, 21\%) }\end{array}$ \\
\hline
\end{tabular}

ST= Systems Thinking

${ }^{*} \mathrm{~N}$ corresponds to the number of respondents. Percentages are calculated out of a total of 62 respondents.

effective capacity building on applying ST tools in LMICs is relatively weak (35), health education leaders on a global level recommended incorporating ST as a core domain in public health curricula and as a competency of health research training (36-38). These calls support suggestions from this study to teach ST approaches in public health graduate programs in the region.

Effective application of ST may also require additional skills to those usually mastered by health systems stakeholders. For example, one of the core elements of ST is coordinating and managing partnerships, which was a perceived challenge in this study, perhaps due to underlying resistance to change long established norms, habits and assumptions; or lack of appreciation for the advantage and need to build and nurture functioning partnerships and networks (39). One opportunity to foster learning and collaboration among health systems stakeholders is the Global Symposia on Health Systems Research (HSR). The Second Global Symposium on HSR in 2012 highlighted the increased interest in applying ST and complex adaptive systems methods and tools. What was obvious, however, was the very limited participation from the EMR.

Interestingly, a commonly mentioned challenge to the application of ST was the perceived notion of its costliness. While it could be argued that ST per se does not cost anything, lack of funding might interfere with building the technical capacity to adopt a ST approach or funding activities related to convening health systems stakeholders and undertaking rigorous and iterative evaluation efforts. Revisiting traditional funding categories to explicitly encourage a more integrative, systems-based view of financing and reforming the way international funds are channelled to LMICs, for example, by allocating a certain proportion to local institutions as core funding, are possible approaches to address this barrier $(1,32)$. Finally, findings emphasized the need to address political and social factors that may influence the adoption and use of ST, such as lack of political support or enabling environment to facilitate and encourage its use. These challenges were also previously reported to limit the use of systems approaches in public health (1). This is especially important in LMICs, where these challenges are often compounded by competing political interests and resistance to change, which were previously shown to interfere with the use of evidence in policy-making in the region $(21,22)$. Findings repeatedly stressed the central role of the government for advancing the application of ST concepts and tools, for example through pushing for governmental reforms or establishing a central body at the government level for the application of ST. Similarly, the need for transformational leadership emerged as an overarching theme for ST strategies in previous studies $(36,40)$. Additionally, participatory governance and fostering peoplecentred health systems, through incorporating people's voices in shaping health systems were recently emphasized at the Third Global Symposium on HSR (2014) (41).

\section{Limitations}

This study has some limitations that should be acknowledged. First, given the uneven sample size across countries, one limitation of the study is that only those who were accessible at the time of selection had a chance of being selected (42). This was probably due to the busy time schedule of participants for conducting the interview in some countries, which we tried to overcome by sending reminders and giving respondents the option to respond by email. Nevertheless, the sample size approached the initial target of interviewing 8-15 respondents per country based on the sampling frame. Another limitation is the different data collection methods used for gathering the perspectives of key informants. While previous studies demonstrated the comparability of phone interviews to face-to-face interviews $(25,43)$ and the comparability of self-administered surveys with interviews $(27,28)$; using different modes of data collection could create a potential bias regarding the nature of the responses obtained (31). However, self-administered questionnaires represented only $24 \%$ of the responses and we did not notice any major discrepancies between the responses provided by any group. In addition, it is worth highlighting that this study is mainly exploratory and was not meant to generate any 
representative findings.

\section{Conclusion}

At a time when the entire world is looking at LMICs to strengthen their health systems and make adequate progress towards achieving the Millennium Development Goals (MDGs), it is critical to ensure that efforts to strengthen health systems take into account their complex and dynamic nature $(5,11)$. ST has the potential to make big strides in improving the way health systems are functioning, including prospects for more efficient and equitable provision of health services and better health.

As the recent political changes continue to unfold in several countries of the EMR, there will be important implications and opportunities for the development of health systems, including whether and how ST concepts can be applied. With several countries moving into post-conflict conditions, the challenges, as well as the prospects, for using ST substantially increase. The hope is to guard against the usual "quick fix" mentality that often dominates, as experience showed in other countries (44). Instead, with the opportunity to rethink, rebuild and break-free from historical constraints, ST could offer a unique opportunity to reshape the way policy is made and health services are provided.

\section{Acknowledgements}

Authors would like to thank all participants in this study. Also, thanks for the Alliance for Health Policy and Systems Research for supporting this study.

\section{Ethical issues}

Institutional Ethical Review Board (IRB) approval was obtained prior to data collection from the American University of Beirut, including the form of consent that was used in the study. For self-administered questionnaires, the consent form was sent to participants via email. Participants' reply to the email indicating their agreement to participate was documented and considered as their consent to participate in the study. Oral consent was obtained for phone interviews and written consent for face-to-face interviews.

Competing interests

The authors declare that they have no competing interests.

\section{Authors' contributions}

All authors meet criteria for authorship. All authors approved this version of the article for publication. FEJ and TA contributed to the conception, design, and interpretation of the data as well as to drafting and critically revising the article. NA and DJ contributed to acquisition of data, analysis, interpretation as well as drafting and critically revising the article. MJ contributed to acquisition of data and drafting the article.

\section{Authors' affiliations}

${ }^{1}$ Department of Health Management and Policy, American University of Beirut, Beirut, Lebanon. ${ }^{2}$ Knowledge to Policy (K2P) Center, Faculty of Health Sciences, American University of Beirut, Beirut, Lebanon. ${ }^{3}$ Center for Systematic Reviews of Health Policy and Systems Research (SPARK), American University of Beirut, Beirut, Lebanon. ${ }^{4}$ Research, Advocacy and Public Policy-Making, Issam Fares Institute for Public Policy and International Affairs, American University of Beirut, Beirut, Lebanon. ${ }^{5}$ Department of Clinical Epidemiology and Biostatistics, McMaster University, Hamilton, Ontario, Canada. ${ }^{6}$ Alliance for Health Policy and Systems Research, World Health Organization, Geneva, Switzerland.

\section{References}

1. Trochim WM, Cabrera DA, Milstein B, Gallagher RS, Leischow SJ. Practical challenges of systems thinking and modeling in public health. Am J Public Health 2006; 96: 538-46. doi: 10.2105/ ajph.2005.066001
2. Leischow SJ, Best A, Trochim WM, Clark PI, Gallagher RS, Marcus SE, et al. Systems thinking to improve the public's health. Am J Prev Med 2008; 35: S196-203.

3. Adam T. Advancing the application of systems thinking in health. Health Res Policy Syst 2014; 12: 50. doi: 10.1186/1478-450512-50

4. Jansen MWJ, van Oers HAM, Kok G, de Vries NK. Public health: disconnections between policy, practice and research. Health Res Policy Syst 2010; 8: 37. doi: 10.1186/1478-4505-8-37

5. de Savigny D, Adam T. Systems thinking for health systems strengthening. Alliance for Health Policy and Systems Research. Geneva: World health Organization: 2009.

6. Swanson RC, Bongiovanni A, Bradley E, Murugan V, Sundewall $\mathrm{J}$, Betigeri A, et al. Toward a consensus on guiding principles for health systems strengthening. PLoS Med 2010; 7: e1000385. doi: 10.1371/journal.pmed.1000385

7. Chee G, Pielemeier N, Lion A, Connor C. Why differentiating between health system support and health system strengthening is needed. Int $J$ Health Plann Manage 2012; 28: 85-94. doi: 10.1002/hpm.2122

8. Kamuzora P, Gilson L. Factors influencing implementation of the Community Health Fund in Tanzania. Health Policy Plan 2007; 22: 95-102. doi: 10.1093/heapol/czm001

9. Agyepong IA, Kodua A, Adjei S, Adam T. When 'solutions of yesterday become problems of today': crisis-ridden decision making in a complex adaptive system (CAS)--the Additional Duty Hours Allowance in Ghana. Health Policy Plan 2012; 27: iv2031. doi: 10.1093/heapol/czs083

10. de Savigny D, Webster J, Agyepong IA, Mwita A, Bart-Plange C, Baffoe-Wilmot A, et al. Introducing vouchers for malaria prevention in Ghana and Tanzania: context and adoption of innovation in health systems. Health Policy Plan 2012; 27: iv3243. doi: 10.1093/heapol/czs087

11. Paina L, Peters DH. Understanding pathways for scaling up health services through the lens of complex adaptive systems. Health Policy Plan 2012; 27: 365-73. doi: 10.1093/heapol/czr054

12. Adam T, Hsu J, de Savigny D, Lavis JN, Røttingen JA, Bennett $S$. Evaluating health systems strengthening interventions in lowincome and middle-income countries: are we asking the right questions? Health Policy Plan 2012; 27: iv9-19. doi: 10.1093/ heapol/czs086

13. World Health Organization (WHO). World Health Report 2000: health systems: improving performance. Geneva: World health Organization; 2000.

14. Sterman JD. Learning from evidence in a complex world. Am J Public Health 2006; 96: 505-14. doi: 10.2105/AJPH.2005.066043

15. Holden LM. Complex adaptive systems: concept analysis. J AdV Nurs 2005; 52: 651-7. doi: 10.1111/j.1365-2648.2005.03638.x

16. Shiell A, Hawe P, Gold L. Complex interventions or complex systems? Implications for health economic evaluation. BMJ 2008; 336: 1281-3. doi: 10.1136/bmj.39569.510521.ad

17. Atun R. Health systems, systems thinking and innovation. Health Policy Plan 2012; 27: iv4-8. doi: 10.1093/heapol/czs088

18. Xiao Y, Zhao K, Bishai DM, Peters DH. Essential drugs policy in three rural counties in China: What does a complexity lens add? Soc Sci Med 2012; 93: 220-8. doi: 10.1016/j. socscimed.2012.09.034

19. World Health Organization Regional Office for the Eastern Mediterranean. The Work of WHO in the Eastern Mediterranean Region Annual Report of the Regional Director. 2013. [cited 2014 October 3]. Available from: http://applications.emro.who. int/docs/RD_annual_Rep_2014_15459_EN.pdf?ua=1

20. Lavis JN, Hammill AC, Bourgeault IL, Stoddart GL. The supply, distribution and working context of health professionals: Why do things (almost) never change? Ontario Health Promotion E-Bulletin; 2007.

21. El-Jardali F, Lavis JN, Ataya N, Jamal D, Ammar W, Raouf S. Use of health systems evidence by policymakers in eastern Mediterranean countries: views, practices, and contextual influences. BMC Health Serv Res 2012; 12: 200. doi: 10.1186/1472-6963-12-200

22. El-Jardali F, Lavis JN, Ataya N, Jamal D. Use of health systems 
and policy research evidence in the health policymaking in eastern Mediterranean countries: views and practices of researchers. Implement Sci 2012; 7: 2. doi: 10.1186/1748-59087-2

23. World Health Organization (WHO). Everybody business: strengthening health systems to improve health outcomes: WHO's framework for action. Geneva: WHO; 2007.

24. Wilczynski NL, Haynes RB, Lavis JN, Ramkissoonsingh R, Arnold-Oatley AE. Optimal search strategies for detecting health services research studies in MEDLINE. CMAJ 2004; 171: 117985.

25. Carr EC, Worth A. The use of the telephone interview for research. Nursing Times Research 2001; 6: 511-24. doi: 10.1177/136140960100600107

26. Sturges JE, Hanrahan KJ. Comparing telephone and faceto-face qualitative interviewing: a research note. Qualitative Research 2004; 4: 107-18. doi: 10.1177/1468794104041110

27. Hahn EA, Rao D, Cella D, Choi SW. Comparability of interviewand self-administration of the functional assessment of cancer therapy-general (FACT-G) in English- and Spanish-speaking ambulatory cancer patients. Med Care 2008; 46: 423-31. doi: $10.1097 / \mathrm{mlr}$.0b013e3181648e6e

28. Fowler FJ, Gallagher PM, Nederend S. Comparing telephone and mail responses to the CAHPS survey instrument. Consumer Assessment of Health Plans Study. Med Care 1999; 37: MS41-9. doi: 10.1097/00005650-199903001-00005

29. Polit DF, Hungler BP. Nursing research: principles and methods. 4th edition. Philadelphia: Lippincott; 1991.

30. Kendall J.Axial coding and the grounded theory controversy. West J Nurs Res 1999; 21: 743-57. doi: 10.1177/01939459922044162

31. Adam T, de Savigny D. Systems thinking for strengthening health systems in LMICs: need for a paradigm shift. Health Policy Plan 2012; 27: iv1-3. doi: 10.1093/heapol/czs084

32. Bennett S, Agyepong IA, Sheikh K, Hanson K, Ssengooba F, Gilson L. Building the field of health policy and systems research: an agenda for action. PLoS Med 2011; 8: e1001081. doi: 10.1371/journal.pmed.1001081

33. Adam T, Ahmad S, Bigdeli M, Ghaffar A, Røttingen JA. Trends in Health Policy and Systems Research over the Past Decade: Still Too Little Capacity in Low-Income Countries. PLoS One 2011; 6: e27263. doi: 10.1371/journal.pone.0027263

34. Saleh SS, Alameddine MS, Natafgi NM, Mataria A, Sabri B,
Nasher J, et al. The path towards universal health coverage in the Arab uprising countries Tunisia, Egypt, Libya, and Yemen. Lancet 2014; 383: 368-81. doi: 10.1016/s0140-6736(13)62339-9

35. Kwamie A, van Dijk H, Agyepong IA. Advancing the application of systems thinking in health: realist evaluation of the Leadership Development Programme for district manager decision-making in Ghana. Health Res Policy Syst 2014; 12: 29. doi: 10.1186/14784505-12-29

36. Swanson RC, Cattaneo A, Bradley E, Chunharas S, Atun R, Abbas $\mathrm{KM}$, et al. Rethinking health systems strengthening: key systems thinking tools and strategies for transformational change. Health Policy Plan 2012 27: iv54-61. doi: 10.1093/ heapol/czs090

37. Frenk J, Chen L, Bhutta ZA, Cohen J, Crisp N, Evans T, et al. Health professionals for a new century: transforming education to strengthen health systems in an interdependent world. Lancet 2010; 376: 1923-58. doi: 10.1016/s0140-6736(10)61854-5

38. Calhoun JG, Ramiah K, Weist EM, Shortell SM. Development of a core competency model for the Master of Public Health degree. Am J Public Health 2008; 98: 1598-607. doi: 10.2105/ ajph.2007.117978

39. Willis CD, Riley BL, Best A, Ongolo-Zogo P. Strengthening health systems through networks: the need for measurement and feedback. Health Policy Plan 2012; 27: iv62-6. doi: 10.1093/ heapol/czs089

40. Zhang X, Bloom G, Xu X, Chen L, Liang X, Wolcott SJ. Advancing the application of systems thinking in health: managing rural China health system development in complex and dynamic contexts. Health Res Policy Syst 2014; 12: 44. doi: 10.1186/1478-4505-12-44

41. Sheikh K, Ranson MK, Gilson L. Explorations on people centredness in health systems. Health Policy Plan 2014; 29: ii15. doi: 10.1093/heapol/czu082

42. Onwuegbuzie AJ, Leech NL. A call for qualitative power analyses. Qual Quant 2007; 41: 105-21. doi: 10.1007/s11135-005-1098-1

43. Bowling A. Mode of questionnaire administration can have serious effects on data quality. J Public Health (Oxf) 2005; 27: 281-91. doi: 10.1093/pubmed/fdi031

44. McPake B, Brikci N, Cometto G, Schmidt A, Araujo E. Removing user fees: learning from international experience to support the process. Health Policy Plan 2011; 26: ii104-17. doi: 10.1093/ heapol/czr064

\section{Appendix 1. Questions}

1. What does Systems Thinking (ST) mean to you? In reality, how applicable is the concept of ST in addressing health system issues in your country?

2. Is ST different from your usual practice in designing and evaluating interventions? If so, how?

3. Do you think that the application of ST can really benefit health systems in your country? Explain.

4. Can you give an example where ST was used for addressing health priorities in your country? What was the end result?

5. Can you give an example where ST was not used for addressing health priorities in your country but was needed? What was the end result?

6. To your knowledge, which of the "Ten Steps to Systems Thinking" are most widely used in your country? Reflect on your experience.

a. How are the first 4 steps for designing interventions applied?

b. How are the last 6 steps for evaluating interventions applied?

7. Are the "Ten Steps to Systems Thinking" practical in your country? How can the proposed steps better be adapted to the context of your country? What are the main challenges to implement the ten steps (e.g. method deficiencies, practicalities etc.)?

8. What are main challenges to applying the approach of ST in your country for addressing health priorities (e.g. contexts and political issues)?

9. How can synergies (a "synergy" is a situation where different entities combine advantageously) across interventions, including several stakeholders, be effectively made in your country? (Examples on synergies include coordination across different ministries or across different departments in the same organization).

10. What are existing enablers of applying ST in your country? What are some entry points (e.g. levels at which ST can be practiced) for ST in your country?

11. In your opinion, what does it take for your country to apply ST for addressing pressing health system issues?

12. What tools/methods do you need to help you apply ST to address health priorities? 